\title{
Fluid Characteristics of Biodiesel Produced from Palm Oil with Various Initial Water Contents
}

\author{
Cherng-Yuan Lin * ${ }^{(1)}$ and Lei Ma
}

check for

updates

Citation: Lin, C.-Y.; Ma, L. Fluid Characteristics of Biodiesel Produced from Palm Oil with Various Initial Water Contents. Processes 2021, 9, 309. https://doi.org/10.3390/pr9020309

Academic Editor: Sebastián Sánchez Villasclaras

Received: 30 December 2020

Accepted: 4 February 2021

Published: 7 February 2021

Publisher's Note: MDPI stays neutral with regard to jurisdictional claims in published maps and institutional affiliations.

Copyright: (c) 2021 by the authors. Licensee MDPI, Basel, Switzerland. This article is an open access article distributed under the terms and conditions of the Creative Commons Attribution (CC BY) license (https:/ / creativecommons.org/licenses/by/ $4.0 /)$.
Department of Marine Engineering, National Taiwan Ocean University, Keelung 202, Taiwan; awpcsawp@yahoo.com.tw

* Correspondence: Lin7108@ntou.edu.tw; Tel.: +886-2-24622307

Abstract: Biodiesel is regarded as a significant alternative fuel to petrodiesel due to its excellent combustion features and renewable character. The water content in the reactant mixtures needs to be considered so as to retard the conversion rate and it is suggested to be kept as low as possible. The fluid characteristics of biodiesel might be affected by initial water content; however, the optimum ratio of water content added to raw oil for achieving superior fluid characteristics of biodiesel has not yet been studied. Hence, this study empirically investigated the influences of the initial water content added to raw feedstock oil on the fluid characteristics of biodiesel. The experimental results show that an adequate amount of water content in the reactant mixture was found effective for improving the transesterification reaction and, in turn, the fluid characteristics. The biodiesel made from raw oil with 0.05 wt. \% water content added was observed to bear the lowest water content, acid value, and cold filter plugging point (CFPP) and, therefore, superior fluidity at low temperatures. The lower CFPP of biodiesel is attributed to its more unsaturated fatty acids and lower iodine value. In addition, the biodiesel produced from feedstock oil with $0.02 \mathrm{wt}$. \% water added was observed to have the lowest iodine value but the highest kinematic viscosity. The optimum content of initial water added to palm oil for superior fluid characteristics of the biodiesel product is thus suggested to be in the range between 0.02 wt. $\%$ and 0.05 wt. $\%$.

Keywords: fluid characteristics; fatty acid methyl esters; cold filter plugging point; water content; iodine value

\section{Introduction}

Biodiesel has been used globally to partially replace petrodiesel for transportation and power sources due to its advantages of superior combustion characteristics, lack of polycyclic aromatic hydrocarbons (PAHs), low emissions of sulfur oxides (SOx) and particulate matters (PM), and excellent biodegradability [1]. Biodiesel also exhibits excellent lubricity for moving engine parts after only $2 \mathrm{wt}$. \% biodiesel is added into diesel [2]. Regarding the reduction of greenhouse gas effects, biodiesel composed of $10 \%$ less elemental carbons than petrodiesel emits much less $\mathrm{CO}_{2}$ gas to the atmosphere during the burning process [3]. A strong alkaline catalyst transesterification is frequently used to produce biodiesel, which is ascribed to a rapid reaction rate and satisfactory fuel characteristics [4]. The initial water and free fatty acids contents in the reactant mixture are considered to be as low as possible. For example, it is suggested that the free fatty acids content, water content, and acid value of feedstock oils should be lower than $0.5 \mathrm{wt}$. \%, $0.06 \mathrm{wt}$. \%, and $1 \mathrm{mg} \mathrm{KOH} / \mathrm{g}$, respectively, to achieve a higher extent of transesterification reaction and also avoid occurrence of saponification during the reaction $[5,6]$. Chanakaewsomboon et al. [7] investigated the effect of water content in the range between $0.1 \mathrm{wt}$. \% and $1 \mathrm{wt}$. \% on the saponification mechanism through the alkaline-catalyzed transesterification of refined palm oil. A weaker soap film was formed with the addition of water content in the reactant mixture of transesterification, which increased the washing loss of crude biodiesel production. The transesterification reaction of rapeseed oil was catalyzed by 
imidazolium ionic liquids (ILs) to investigate the effect of the deactiviation of water on catalytic activity [8]. The authors found that the increase of water content from $1 \mathrm{wt}$. \% to $5 \mathrm{wt}$. \% did not cause the variation of the yield of fatty acid methyl ester (FAME) at $130{ }^{\circ} \mathrm{C}$. In contrast, some studies found that sufficient water content, such as $2.5 \mathrm{wt}$. \%, in raw oil might enhance hydrolysis of fatty acids, which leads to activation of the transesterification reaction [9]. Sun et al. [10] studied the effect of water content in wet Nannochloropsis oceanica on 1-butyl-3-methylimidazolium hydrogen sulfate ([Bmim] $\left.\left[\mathrm{HSO}_{4}\right]\right)$-catalyzed in situ transesterification. They found that when the water content was increased from $0 \mathrm{wt}$. \% to $15 \mathrm{wt} . \%$, the total energy of the produced biodiesel increased by $10.6 \%$. Park et al. [11] applied solvothermal in situ transesterification to produce biodiesel from wet spent coffee grounds (SCG) without catalyst. They observed that the water content of SCG played a positive role for the hydrolysis of 1,2-dichloroethane (DCE) because of the bimolecular substitution mechanism.

Using the lowest water content in raw oil is frequently recommended to achieve superior fluid characteristics in a biodiesel product while some studies suggest that adequate water content might enhance the transesterification process and thus biodiesel characteristics. However, there are few studies in the relevant literature on the effects of water content added to feedstock oil on the mechanism of the transesterification reaction and the fluid characteristics of biodiesel products. Variations in the fluid characteristics of biodiesel with initial water contents added in particular not been experimentally investigated. Hence, this study measured and discussed the fluid properties, such as kinematic viscosity and cold filter plugging point (CFPP) owing to various levels of water content added to palm oil. The optimum water addition into raw feedstock oil for the improvement of fluid characteristics of biodiesel was also analyzed in this study.

\section{Experimental Details}

\subsection{Production of Palm-Oil Biodiesel Added with Water Content}

A magnetic electric heating agitator (Model SP47235-60, Thermolyne Inc., Barnstead, $\mathrm{NH}$, USA) was used to evenly stir the palm feedstock oil at $25{ }^{\circ} \mathrm{C}$ with added water contents in the range between $0.02 \mathrm{wt} . \%$ and $0.12 \mathrm{wt}$. $\%$ and preheat to $60^{\circ} \mathrm{C}$. One weight percentage of the strong alkaline catalyst $\mathrm{NaOH}$ of palm oil was stirred with methanol for $10 \mathrm{~min}$. The molar ratio of palm oil to methanol was set at 1:6. The mixture of catalyst and methanol was then poured into a reacting tank and stored with the palm oil and water to undergo a transesterification reaction using a mechanical homogenizer (Model Ultra-Turrax T50, IKA Inc., Germany) at a speed of $6000 \mathrm{rpm}$ for $30 \mathrm{~min}$. Glacial acetic acid was then mixed with the crude biodiesel product to neutralize its $\mathrm{pH}$ value. The biodiesel was then centrifuged to separate biodiesel in the upper layer and glycerol in the lower layer. The unreacted methanol and volatile impurities were vaporized away by heating the biodiesel to $70{ }^{\circ} \mathrm{C}$ for $30 \mathrm{~min}$. Distilled water of $10 \mathrm{vol}$. \% of the crude biodiesel at $50{ }^{\circ} \mathrm{C}$ was then used to wash the biodiesel for $5 \mathrm{~min}$. The biodiesel mixture was then kept motionless for $15 \mathrm{~min}$ to separate the washed biodiesel from water. A distillation process then ensued in which the biodiesel was heated at $105^{\circ} \mathrm{C}$ for $30 \mathrm{~min}$ to remove volatile matter. The biodiesel, also termed as palm oil methyl esters (PME), was then ready for the analysis of its fluid characteristics.

\subsection{Measurement of Fluid Characteristics of Biodiesel from Feedstock Oil with Water}

The palm-oil biodiesel with various initial water contents was produced through strong alkaline catalyst transesterification. The fluid characteristics of the PME, such as the acid value and cold filter plugging point (CFPP), were measured. Gas-liquid chromatography (Model Trace GC 2000, Thermoquest Ce Instruments, Egelsbach, Germany) was used to analyze the fatty acid compositions of the biodiesel produced through transesterification. The ester content of fatty acid methyl esters was determined in accordance with the method from EN 14103. An automatic titration meter (Model 785 DMP Titrino, Metrohm AG, Switzerland), together with a magnetic stirrer (Model PC-420D, Corning Inc., Corning, NY, 
USA), were used to measure the acid value and iodine value of the biodiesel. The acid value was defined as the amount of potassium hydroxide $(\mathrm{KOH})$ required (in $\mathrm{mg}$ ) to neutralize $1 \mathrm{~g}$ of free fatty acid in a lipid. A higher acid value implies a faster deterioration of the fuel characteristics. The acid value of the tested biodiesel was measured by titration with $0.01 \mathrm{~N} \mathrm{KOH}$ solution until the appearance of a pink color based on the standard method of EN 14104. The iodine values of the tested biodiesel were determined by titration with $0.01 \mathrm{~N}$ sodium thiosulfate compound until the appearance of a light blue color. The water content in the biodiesel was analyzed using volumetric Karl Fischer titration (Model DL-31, Mettler-Toledo Inc., Greifensee, Switzerland), based on the coulometric method [9]. In order to determine the sample's moisture, the Karl Fischer solution was titrated into the biodiesel sample until the first trace of excess iodine appears.

The kinematic viscosity in a unit of $\mathrm{mm}^{2} / \mathrm{s}(\mathrm{cSt})$ of the biodiesel sample was analyzed by a capillary viscometer (Model No.1 K698, Cannon Inc., Ota-ku City, Tokyo, Japan) at $40{ }^{\circ} \mathrm{C}$ within a constant-temperature water tank. The cold filter plugging point is a significant indicator for low-temperature fluidity for liquid fuel, particularly for biodiesel. The temperature at which liquid fuel cannot flow through a specified fuel filter is defined as the CFPP of the fuel sample. A CFPP analyzer (Model K45900, Koehler Instrument Inc., Bohemia, NY, USA) was used to analyze the CFPP of the PME samples based on the ASTM D6371 standard method.

\section{Results and Discussion}

This study experimentally analyzed the variations of fluid characteristics in biodiesel with initial water contents added in the range between $0.02 \mathrm{wt}$. \% and $0.12 \mathrm{wt}$. \%. The experimental data were reported based on the mean values of at least three measurements. The experimental uncertainties of the water, acid value, iodine value, CFPP, FAME, and kinematic viscosity were $\pm 1.15 \%, \pm 2.38 \%, \pm 2.73 \%, \pm 3.79 \%, \pm 0.32 \%$, and $\pm 2.41 \%$, respectively. The experimental results of the fluid characteristics are explained and discussed below.

\subsection{Water Content in the Biodiesel}

The variation of the water content in the biodiesel product with the initial water content added into the raw palm oil appeared to show a reverse parabolic relationship, as can be seen in Figure 1. The lowest water content in the biodiesel product was found with an initial added water content of $0.05 \mathrm{wt}$. \% in the raw palm oil. Hence, it can be inferred that adding an appropriate quantity of water to the raw oil can enhance the process of transesterification, a finding similar to the results of Tsuchiya et al. [12]. It was found that the added water facilitated the hydrolysis of lipids during the process of the transesterification reaction, resulting in the simultaneous increase of the amounts of free fatty acids and water [13]. Consequently, some water still existed even after the biodiesel was vaporized to remove its volatile matter and the water remaining at the end of the biodiesel production process. In contrast, when the initial water content added was too low to sufficiently enhance the hydrolysis reaction and produce enough $\mathrm{OH}^{-}$radicals to allow the transesterification to proceed, the free fatty acids in the raw oil were hydrolyzed to form water, although most triglycerides were converted to produce fatty acid methyl esters. Therefore, higher water content in the biodiesel product than the corresponding water amount initially added to the palm oil was observed for those cases where the water added was lower than $0.05 \mathrm{wt}$. \%, as shown in Figure 1. It was also found that higher fatty acid methyl esters were formed after $0.05 \mathrm{wt}$. \% water content was added to raw oil in Table 1. The FAME contents of the biodiesel made from palm oil with various water contents added were analyzed based on the EN 14103 method. The FAME produced from palm oil with 0.05 wt. \% water reached $97.3 \%(\mathrm{~m} / \mathrm{m})$, which is above the limit of $96.5 \mathrm{wt}$. \% of the EN biodiesel standard. The contents of the oleic acid (C18:1), palmitic acid, and linolenic acid ranked the highest among these fatty acids, amounting to $45.07 \mathrm{wt}$. \%, $36.93 \mathrm{wt}$. \%, and $11.68 \mathrm{wt}$. \%, respectively, as shown in Table 1 . The FAME analysis of the fatty acid 
compositions revealed the PME is a rather adequate alternative fuel to petrodiesel for compression ignition engines [14].

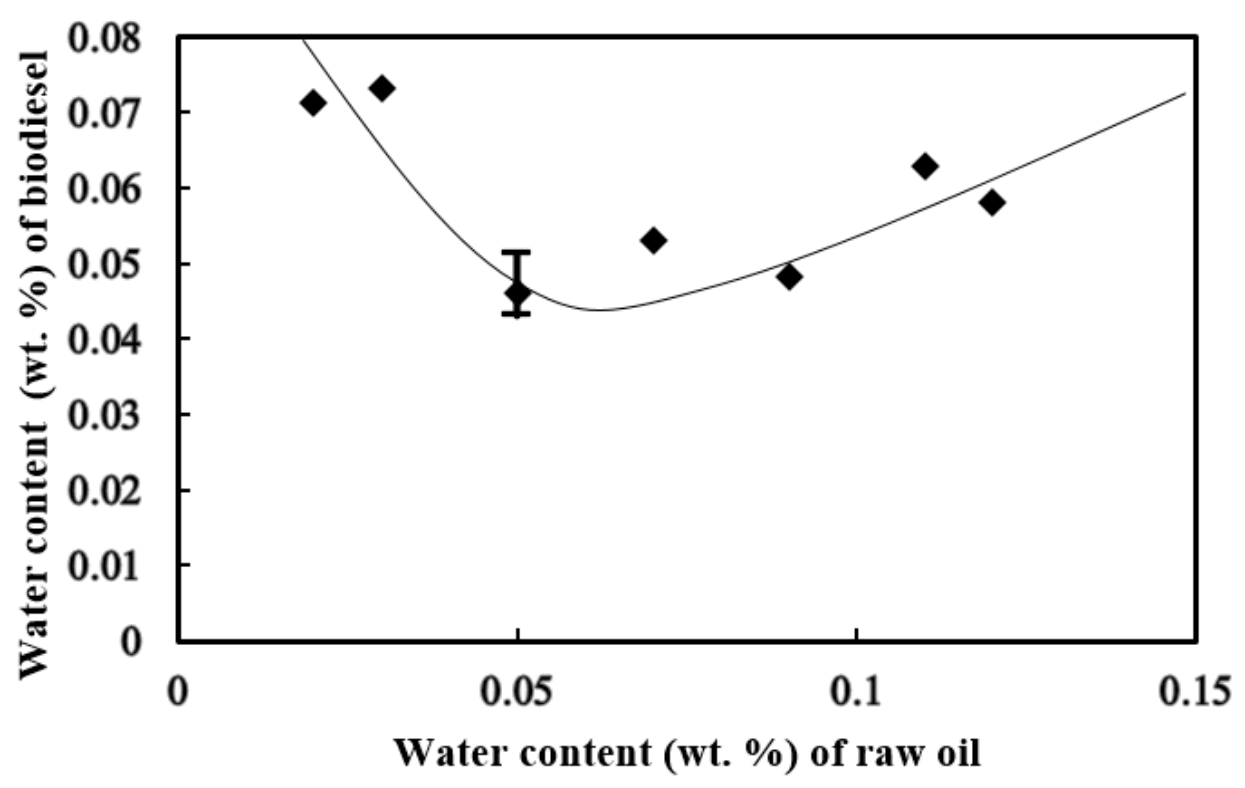

Figure 1. Variations of the water content of the biodiesel product with the initial water content in the raw palm oil.

Table 1. Composition of fatty acid methyl esters (FAME) produced from palm oil with 0.05 wt. \% initial water content added.

\begin{tabular}{cc}
\hline Fatty Acids Chemical Structure & Composition (wt. \%) \\
\hline Myristic acid C14:0 & 1.14 \\
Palmitic acid C16:0 & 36.93 \\
Palmitoleic acid C16:1 & 0.22 \\
Stearic acid C18:0 & 3.95 \\
Oleic acid C18:1 & 45.07 \\
Linoleic acid C18:2 & 11.68 \\
Linolenic acid C18:3 & 0.10 \\
Arachidic acid C20:0 & 0.34 \\
Eicosenoic acid C20:1 & 0.17 \\
Behenic acid C22:0 & 0.17 \\
Erucic acid C22:1 & 0.05 \\
Lignoceric acid C24:0 & 0.10 \\
Docosahexaenoic acid C22:6 & 0.06 \\
Total saturated fatty acids & 42.63 \\
Monounsaturated fatty acids & 45.51 \\
Polyunsaturated fatty acids & 11.84 \\
Total FAME & 97.30 \\
\hline
\end{tabular}

\subsection{Acid Value of the Biodiesel}

The lowest acid values of the biodiesel from raw oil with various water contents added are shown in Figure 2. Eze et al. [15] and Alptekin and Canalci [16] found that water, which can be produced from the mixing process of a strong alkaline catalyst and methanol, can cause a saponification phenomenon once it is mixed with the raw oil prior to transesterification. Therefore, the formation of $\mathrm{OH}^{-}$radicals from the dissociation of water might have promoted the ensuing transesterification reaction of the raw oil with an adequate amount of water added [17]. Moreover, the water content would have facilitated the hydrolysis of the raw oil's fatty acids [18], leading to the production of free fatty acids and thus increasing the acid value [19]. Hence, the higher contents of free fatty acids in 
the biodiesel product were observed to have higher acid values, as shown in Figure 2. It follows that the lowest acid value, accompanied by the lowest water content of the biodiesel, were produced when the $0.05 \mathrm{wt}$. \% initial water content was mixed with the raw oil feedstock, as shown in Figures 1 and 2.

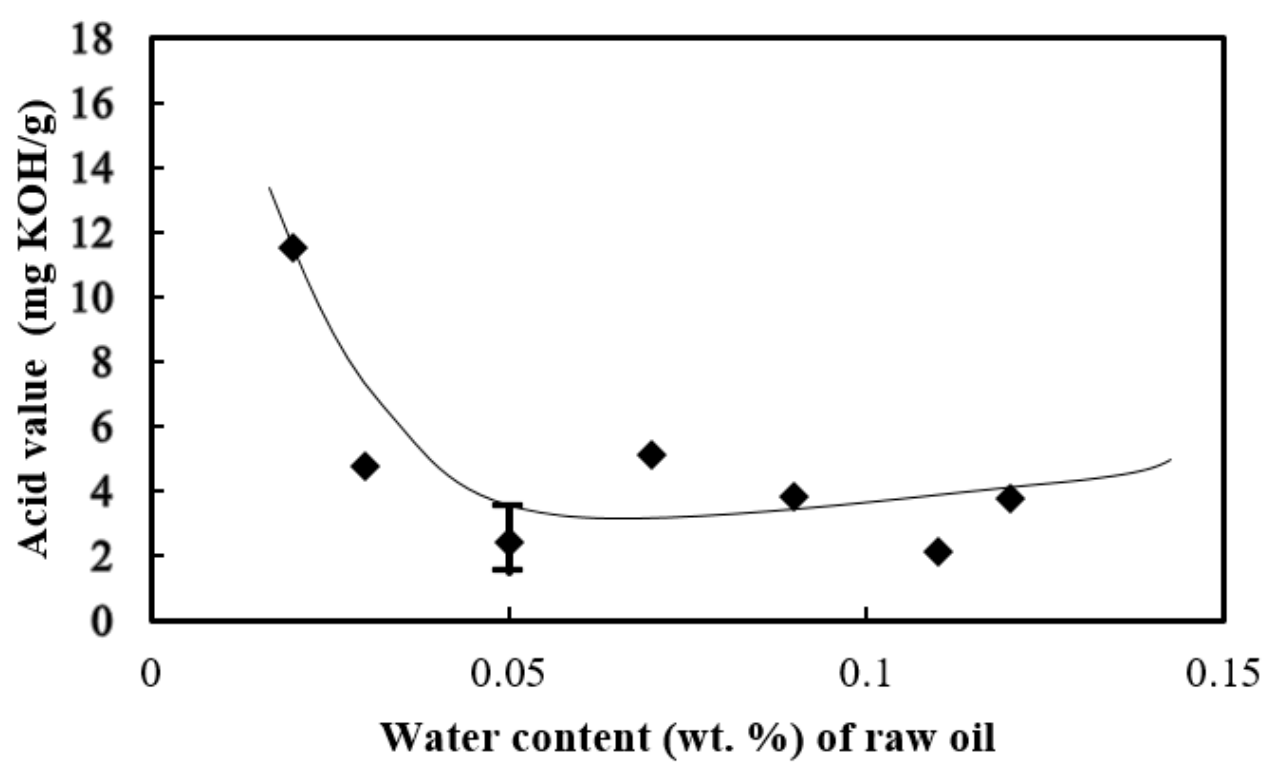

Figure 2. Variations of the acid value of the biodiesel product with the initial water content in the raw palm oil.

\subsection{Iodine Value of the Biodiesel}

The iodine value is defined as the consumption of iodine in grams by $100 \mathrm{~g}$ of lipids through the addition reaction. When the unsaturated fatty acids react with iodine compounds, the lipids with double-bond structures create an addition reaction, leading to production of single-bond structures [20]. Hence, a lipid with a higher iodine value indicates its higher unsaturated content of fatty acids [21]. The palm oil feedstock consisted of more than $80 \mathrm{wt}$. \% of palmitic acid (C16:0), stearic acid (C18:0), oleic acid (C18:1), and linoleic acid (C18:2). The FAME produced through transesterification of the raw palm oil was mostly composed of those four compounds, as shown in Table 1. Hence, a lower iodine value was found for the biodiesel produced from the feedstock oil composed of high saturated fatty acids. These findings agree well with those of Aslam et al. [22]. Lipid oil can be conveniently categorized into three groups based on its iodine value: the drying oil group, with over $140 \mathrm{~g} \mathrm{I} / 100 \mathrm{~g}$ oil; the semi-drying oil group, with $125 \mathrm{~g} \mathrm{I} / 100 \mathrm{~g}$ to $140 \mathrm{~g} \mathrm{I} / 100 \mathrm{~g}$ oil; and the non-drying oil group, with less than $125 \mathrm{~g} \mathrm{I} / 100 \mathrm{~g}$ oil [23]. All of the biodiesel products in this study were of the non-drying oil group due to their iodine values being below $125 \mathrm{~g} \mathrm{I} / 100 \mathrm{~g}$ oil.

The highest iodine value of the PME was observed to be produced from the raw oil with 0.07 wt. \% water added, as shown in Figure 3. However, there was a small difference of $15 \mathrm{~g} \mathrm{I} / 100 \mathrm{~g}$ biodiesel among these biodiesels. All of the iodine values ranged between $52 \mathrm{~g} \mathrm{I} / 100 \mathrm{~g}$ biodiesel and $67 \mathrm{~g} \mathrm{I} / 100 \mathrm{~g}$ biodiesel, which are considerably lower than the $120 \mathrm{~g} \mathrm{I} / 100 \mathrm{~g}$ biodiesel value specified in the EN 14214 biodiesel standard. Hence, there was not much deviation in the contents of unsaturated fatty acids among the biodiesels shown in Figure 3. As shown in Table 1, the content of polyunsaturated fatty acids amounted to only $11.84 \mathrm{wt}$. \%. Lipids with a lower iodine value imply a lower content of unsaturated fatty acids and have a higher degree of oxidation stability [24]. The lowest iodine value found was for the biodiesel made from the raw oil with $0.02 \mathrm{wt}$. \% added initial water content. This is probably because initial water content higher than 0.02 wt. \% would reduce the transesterification extent due to excess hydrolysis of fatty acids, resulting in a mild increase in free fatty acids, acid values, and unsaturated fatty 
acids. In contrast, initial water content lower than $0.05 \mathrm{wt}$. \% caused a reduction in the conversion rate of the palm oil. The concentration of $\mathrm{OH}^{-}$radicals decreased and this was accompanied by an increase in short carbon-chain fatty acids [25]. Hence, a decrease in the unsaturated fatty acids and iodine values appeared, as shown in Figure 3.

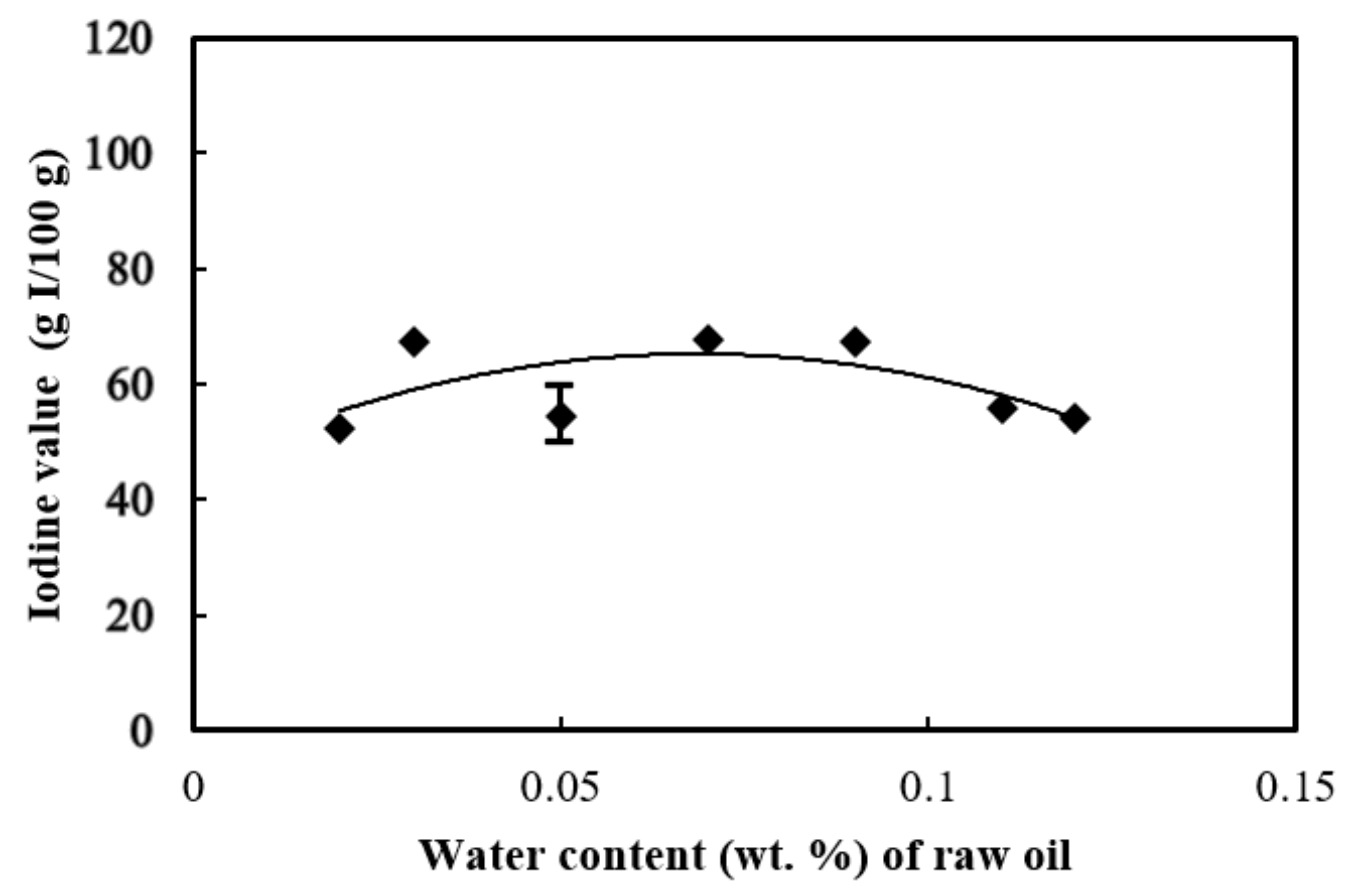

Figure 3. Variations of the iodine value of the biodiesel product with the initial water content in the raw palm oil.

\subsection{Kinematic Viscosity of the Biodiesel}

The viscosity of liquid fuel strongly determines the lubricity of moving mechanical parts, the fuel atomization extent, and, in turn, combustion characteristics [26]. Low viscosity of fuel causes insufficient lubricity on the mechanical part's surface and thus excessive wear or highly accumulated heat. Too high a viscosity causes an increase in friction drag of mechanical moving parts. Lepri et al. [27] suggested that liquid fuel with a higher viscosity tends to produce larger atomized droplets which penetrate longer distances in the combustor. An adequate range of viscosity values, between 3.5 and $5.0 \mathrm{~mm}^{2} / \mathrm{s}$, is specified for commercial biodiesel according to the EN 14214 standard.

The kinematic viscosities of biodiesel ranged between 4.5 and $4.9 \mathrm{~mm}^{2} / \mathrm{s}$, as shown in Figure 4. The highest and lowest kinematic viscosities appeared for biodiesel produced from the raw oil with $0.02 \mathrm{wt}$. \% and $0.11 \mathrm{wt}$. \% water added, respectively. By comparing Figures 3 and 4, an approximately reverse trend between kinematic viscosity and iodine values with added water content can be observed. This finding agrees well with that of Nezihe et al. [28]. Moreover, Giakoumis [29] found that kinematic viscosity is affected by the fatty acid composition of biofuel. Biodiesel, which is composed of longer fatty acids or more saturated fatty acids, appears to have greater kinematic viscosity [30]. Hence, biodiesel made from palm oil has greater kinematic viscosity than those biodiesels made from corn oil, canola oil, rapeseed oil, and soybean oil [26,31], primarily due to the higher content of saturated fatty acids of the PME in those biodiesels. Biodiesel consisting of less unsaturated fatty acids content was produced from palm oil with water content either relatively higher or lower than $0.05 \mathrm{wt}$. \% added, resulting in lower iodine values and correspondingly higher kinematic viscosities for those biodiesels produced from the raw oil with 0.02 wt. \% and 0.12 wt. \% water added, as shown in Figures 3 and 4. 


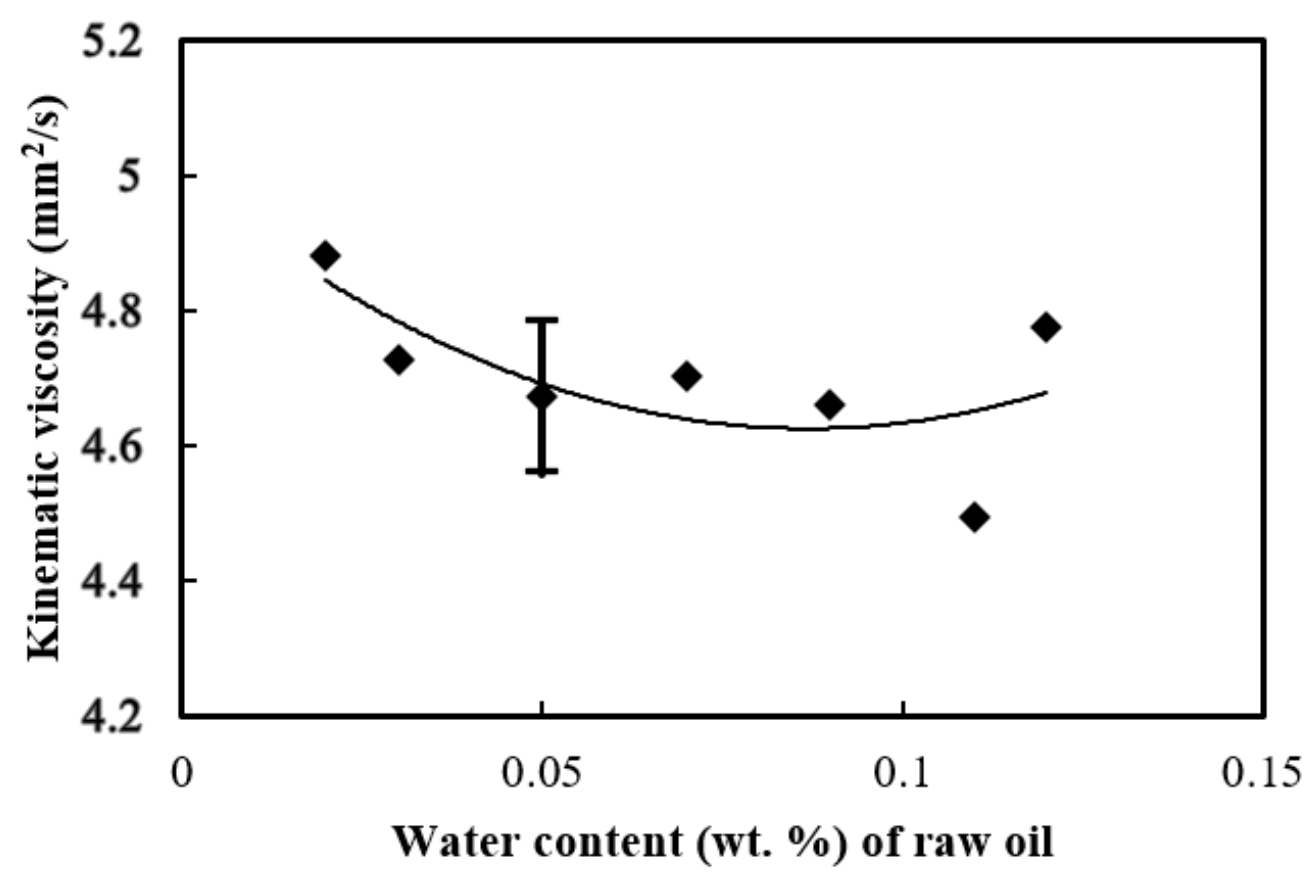

Figure 4. Variations of the kinematic viscosity of the biodiesel product with the initial water content in the raw palm oil.

\subsection{Cold Filter Plugging Point of the Biodiesel}

Sørensen et al. [32] considered that long saturated carbon-chain fatty acid methyl esters are prone to enter a condensed gel state when the temperature of the liquid fuel is reduced. Some liquid fuel at low temperatures tends to produce vague solid sediment which is termed wax crystal [33]. When the solid wax crystals continue to grow in the liquid fuel at even lower temperatures and eventually clog the specified fuel filter, such a corresponding low temperature is defined as the cold filter plugging point of the liquid fuel [34]. The effects of the initial water content added on the CFPP of the biodiesel are shown in Figure 5. The lowest CFPP of $9{ }^{\circ} \mathrm{C}$ occurred for the biodiesel made from the raw oil with $0.05 \mathrm{wt}$. \% initial water added. This was probably because of the larger unsaturated FAME. The combined unsaturated fatty acid content of the biodiesel's oleic acid (C18:1), linoleic acid (C18:2), and linolenic acid (C18:3) produced from the palm oil with $0.05 \mathrm{wt}$. \% initial water added accounted for the highest result of $56.85 \mathrm{wt}$. \% in Table 1. Lv et al. [35] observed that the CFPP of the biodiesel made from palm oil is $16^{\circ} \mathrm{C}$, which is relatively high in comparison with other biodiesels produced from edible vegetable oils, such as rapeseed oil and soybean oil, due to the lower unsaturated fatty acids of palm oil. Wardana et al. [36] found that the CFPP increases with the increase of the amount of long carbon-chain fatty acids. In addition, the lower iodine values, which imply lower amounts of unsaturated fatty acids, corresponded to lower CFPP values for the biodiesel produced by adding $0.05 \mathrm{wt}$. \% initial water, as can be seen by comparing the findings presented in Figures 3 and 5 . 


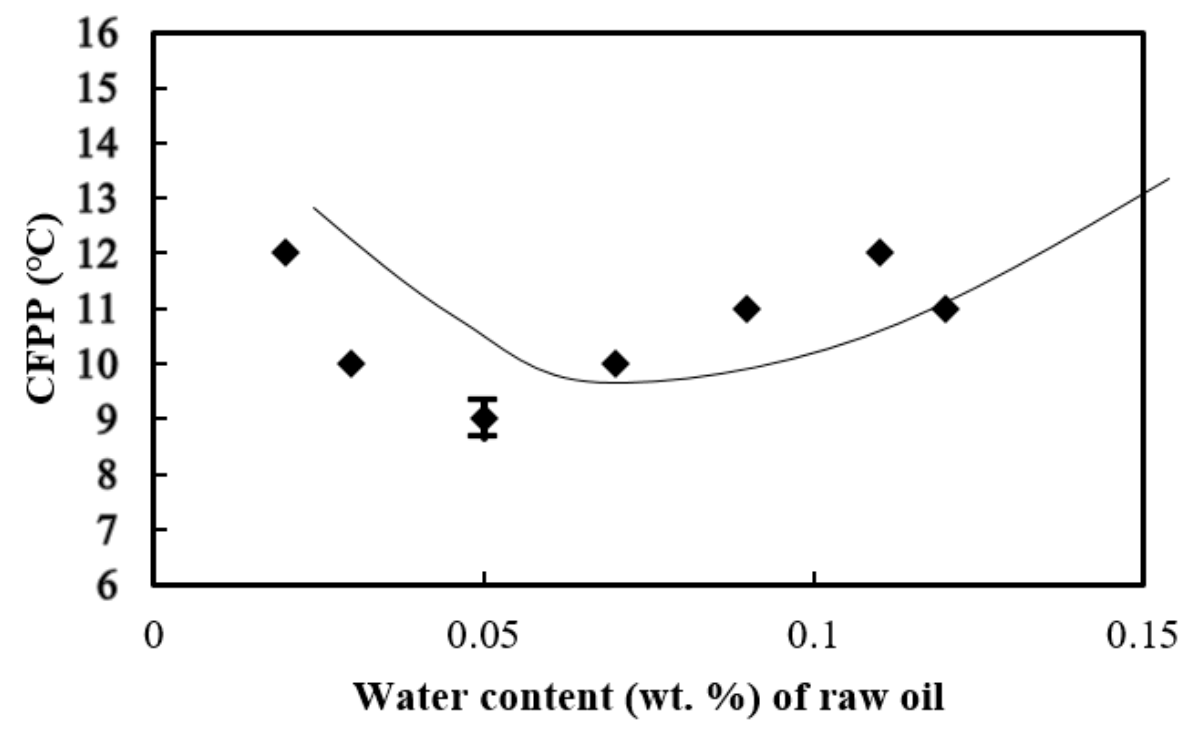

Figure 5. Variations of the cold filter plugging point (CFPP) of the biodiesel product with initial water content in palm oil.

\subsection{Fatty Acid Methyl Esters (FAME) above C14 of the Biodiesel}

Biodiesel is regarded as an adequate alternative fuel to petrodiesel partially due to the similar structure of carbon numbers between these two fuels. Petrodiesel is primarily composed of hydrocarbon compounds larger than C14 and contains heavier compounds than those of petrogasoline. Hence, the weight fraction of fatty acid methyl esters larger than C14 influences the fuel combustion characteristics of biodiesel made from various feedstock materials and production processes. The effects of initial water contents between $0.02 \mathrm{wt} . \%$ and $0.12 \mathrm{wt} . \%$ on the weight fraction of fatty acid methyl esters above C14 are shown in Figure 6. The biodiesel made from palm oil with $0.03 \mathrm{wt}$. \% water added was observed to have the highest weight fraction of fatty acid methyl esters (FAME) above C14. Either an increase or decrease of initial water content from $0.03 \mathrm{wt}$. \% caused a decrease of FAME above C14. This was probably due to the formation of sufficient $\mathrm{OH}^{-}$ radicals from the dissociation of added water content, leading to the enhancement of the transesterification reaction of palm oil with methanol [37,38]. Water content higher or lower than $0.03 \mathrm{wt}$. \% resulted in a lower conversion rate from raw oil and thus lower formation of the FAME above C14, as shown in Figure 6.

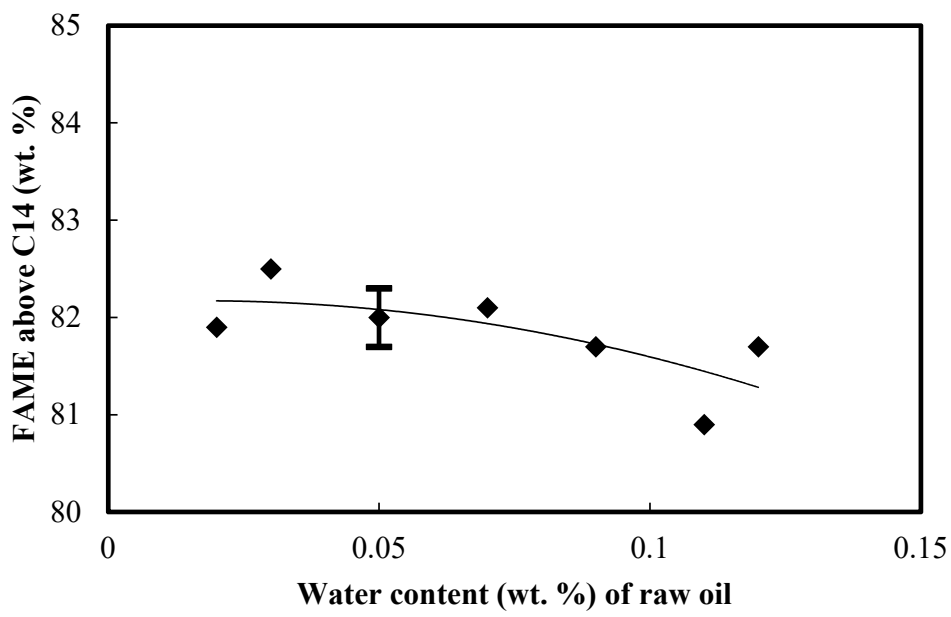

Figure 6. Variations of the fatty acid methyl esters (FAME) above C14 of the biodiesel product with the initial water content in the raw palm oil. 


\section{Conclusions}

This experimental study analyzed the fluid characteristics of biodiesel made from palm oil with various initial water contents added. The major results are summarized below.

(1) Initial water content of $0.05 \mathrm{wt}$. \% added to feedstock oil facilitated the formation of the lowest water content in the biodiesel product. The transesterification reaction was enhanced with adequate water content in the reactant mixture.

(2) Water in raw palm oil enhanced the hydrolysis of fatty acids, causing the production of free fatty acids and increasing the acid value. The lowest acid value of the biodiesel was found when the feedstock oil had $0.05 \mathrm{wt}$. \% initial water added.

(3) The biodiesels produced in this study came from the non-drying oil group, based on their iodine values ranging between 52 and $67 \mathrm{~g} \mathrm{I} / 100 \mathrm{~g}$ biodiesel. The lowest iodine value of biodiesel was produced from the feedstock oil with $0.02 \mathrm{wt}$. \% initial water added, due to the formation of the lowest amount of unsaturated fatty acids.

(4) Biodiesel composed of more long or saturated fatty acids is prone to greater kinematic viscosity. The highest kinematic viscosity corresponding to the lowest iodine value occurred in the FAME made from the feedstock oil with $0.02 \mathrm{wt}$. \% water added.

(5) Biodiesel consisting of more unsaturated fatty acids tends to have a lower cold filter plugging point (CFPP). Biodiesel made from palm oil with $0.05 \mathrm{wt}$. \% water added had the lowest CFPP of $9{ }^{\circ} \mathrm{C}$ and a corresponding lower iodine value due to the formation of more unsaturated fatty acids, of which oleic acid (C18:1), linoleic acid (C18:2), and linolenic acid (C18:3) amounted to $56.85 \mathrm{wt}$. \%. Biodiesel produced from palm oil with $0.03 \mathrm{wt}$ \% initial water added appeared to have the highest content of FAME above C14.

Author Contributions: Conceptualization, C.-Y.L.; methodology, C.-Y.L.; validation, L.M.; investigation, L.M.; resources, C.-Y.L.; data curation, L.M.; writing-original draft preparation, L.M.; writing-review and editing, C.-Y.L.; supervision, C.-Y.L.; project administration, C.-Y.L.; funding acquisition, C.-Y.L. All authors have read and agreed to the published version of the manuscript.

Funding: This research was funded by the Ministry of Science and Technology, Taiwan, grant number MOST 109-2221-E-019-024 and MOST 107-2221-E-019-056-MY2. The APC was funded by National Taiwan Ocean University, Taiwan.

Institutional Review Board Statement: Not applicable.

Informed Consent Statement: Not Applicable.

Data Availability Statement: Data is available in the article or on request from the authors.

Acknowledgments: The financial support from the Ministry of Science and Technology, Taiwan under Contract No: MOST 109-2221-E-019-024 and MOST 107-2221-E-019-056-MY2 is acknowledged.

Conflicts of Interest: The authors declare no conflict of interest.

\section{References}

1. Tan, P.-Q.; Zhong, Y.-M.; Hu, Z.; Lou, D.-M. Size distributions, PAHs and inorganic ions of exhaust particles from a heavy duty diesel engine using B20 biodiesel with different exhaust aftertreatments. Energy 2017, 141, 898-906. [CrossRef]

2. Peng, D.-X. Biodiesel Improves Lubricity of Low-Sulfur Petro-Diesels. Chem. Technol. Fuels Oils 2017, 52, 699-703. [CrossRef]

3. Gharehghani, A.; Mirsalim, M.; Hosseini, R. Effects of waste fish oil biodiesel on diesel engine combustion characteristics and emission. Renew. Energy 2017, 101, 930-936. [CrossRef]

4. Yadav, A.K.; Khan, M.E.; Pal, A. Biodiesel production from oleander (Thevetia Peruviana) oil and its performance testing on a diesel engine. Korean J. Chem. Eng. 2016, 34, 340-345. [CrossRef]

5. Di Bitonto, L.; Pastore, C. Metal hydrated-salts as efficient and reusable catalysts for pre-treating waste cooking oils and animal fats for an effective production of biodiesel. Renew. Energy 2019, 143, 1193-1200. [CrossRef]

6. Shi, W.J.; Liu, H.Q.; Feng, S.B.; Zheng, E.L. Study on preparation of biodiesel with low acid value rapeseed oil. Renew. Energy Resour. 2009, 27, 37-39.

7. Chanakaewsomboon, I.; Tongurai, C.; Photaworn, S.; Kungsanant, S.; Nikhom, R. Investigation of saponification mechanisms in biodiesel production: Microscopic visualization of the effects of FFA, water and the amount of alkaline catalyst. J. Environ. Chem. Eng. 2020, 8, 103538. [CrossRef] 
8. Fan, P.; Xing, S.; Wang, J.; Fu, J.; Yang, L.; Yang, G.; Miao, C.; Lv, P. Sulfonated imidazolium ionic liquid-catalyzed transesterification for biodiesel synthesis. Fuel 2017, 188, 483-488. [CrossRef]

9. Widziewicz-Rzońca, K.; Tytła, M.; Majewski, G.; Rogula-Kopiec, P.; Loska, K.; Rogula-Kozłowska, W. Strongly and loosely bound water in ambient particulate matter-qualitative and quantitative determination by Karl Fischer Coulometric meth-od. Sustainability 2020, 12, 6196. [CrossRef]

10. Sun, Y.; Xu, C.; Igou, T.; Liu, P.; Hu, Z.; Van Ginkel, S.W.; Chen, Y. Effect of water content on [Bmim][HSO4] assisted in-situ transesterification of wet Nannochloropsis oceanica. Appl. Energy 2018, 226, 461-468. [CrossRef]

11. Park, J.; Kim, B.; Son, J.; Lee, J.W. Solvo-thermal in situ transesterification of wet spent coffee grounds for the production of biodiesel. Bioresour. Technol. 2018, 249, 494-500. [CrossRef]

12. Tsuchiya, Y.; Kaneki, Y.; Yamakoshi, Y. $\mathrm{H}_{2} \mathrm{SO}_{4} / \mathrm{CaO}$-Catalyzed Process for Biodiesel Production from High Acid Value Jatropha curcas Crude Oil. J. Chem. Eng. Jpn. 2011, 44, 529-533. [CrossRef]

13. Amoah, J.; Quayson, E.; Hama, S.; Yoshida, A.; Hasunuma, T.; Ogino, C.; Kondo, A. Simultaneous conversion of free fatty acids and triglycerides to biodiesel by immobilized Aspergillus oryzae expressing Fusarium heterosporum lipase. Biotechnol. J. 2017, 12, 1600400. [CrossRef] [PubMed]

14. Singh, R.K.; Sarkar, A.; Chakraborty, J.P. Influence of Alternate Fuels on the Performance and Emission from Internal Combustion Engines and Soot Particle Collection Using Thermophoretic Sampler: A Comprehensive Review. Waste Biomass Valorization 2018, 10, 2801-2823. [CrossRef]

15. Eze, V.C.; Phan, A.N.; Harvey, A.P. Intensified one-step biodiesel production from high water and free fatty acid waste cooking oils. Fuel 2018, 220, 567-574. [CrossRef]

16. Alptekin, E.; Canalci, M. Optimization of transesterification for methyl ester production from chicken fat. Fuel 2011, 90, 2630-2638. [CrossRef]

17. Rorrer, J.E.; Toste, F.D.; Bell, A.T. Mechanism and kinetics of isobutene formation from ethanol and acetone over $\mathrm{Zn}_{\mathrm{x}} \mathrm{Zr}_{\mathrm{y}} \mathrm{O}_{\mathrm{z}}$. ACS Catal. 2019, 9, 10588-10604. [CrossRef]

18. Zhang, X.; Nie, K.; Zheng, Y.; Wang, F.; Deng, L.; Tan, T. Lipase Candida sp. 99-125Coupled with $\beta$-cyclodextrin as additive synthesized the human milk fat substitutes. J. Mol. Catal. B Enzym. 2016, 125, 1-5. [CrossRef]

19. Kara, K.; Ouanji, F.; Lotfi, E.M.; El Mahi, M.; Kacimi, M.; Ziyad, M. Biodiesel production from waste fish oil with high free fatty acid content from Moroccan fish-processing industries. Egypt. J. Pet. 2018, 27, 249-255. [CrossRef]

20. Xu, L.; Zhu, X.; Yu, X.; Huyan, Z.; Wang, X. Rapid and Simultaneous Determination of the Iodine Value and Saponification Number of Edible Oils by FTIR Spectroscopy. Eur. J. Lipid Sci. Technol. 2018, 120, 1700396. [CrossRef]

21. Serra, J.L.; de Cruz Rodrigues, A.M.; de Freitas, R.A.; de Almeida Meirelles, A.J.; Darnet, S.H.; Meller da Silva, L.H. Alternative sources of oils and fats from Amazonian plants: Fatty acids, methyl tocols, total carotenoids and chemical composition. Food Res. Int. 2019, 116, 12-19. [CrossRef]

22. Aslam, M.M.; Khan, A.A.; Cheema, H.M.N.; Hanif, M.A.; Azeem, M.W.; Azmat, M.A. Novel mutant camelina and jatropha as valuable feedstocks for biodiesel production. Sci. Rep. 2020, 10, 1-9. [CrossRef] [PubMed]

23. Tomak, E.D.; Hughes, M.; Yildiz, U.C.; Viitanen, H. The combined effects of boron and oil heat treatment on beech and Scots pone wood properties. Part 1: Boron leaching, thermogravimetric analysis, and chemical composition. J. Mater. Sci. 2011, 46, 598-607. [CrossRef]

24. Vescovi, V.; Rojas, M.J.; Baraldo, A., Jr.; Botta, D.C.; Montes Santana, F.A.; Costa, J.P.; Machado, M.S.; Honda, V.K.; de Lima Camargo Giordano, R.; Tardioli, P.W. Lipase-catalyzed production of biodiesel by hydrolysis of waste cooking oil followed by esterification of free fatty acids. J. Am. Oil Chem. Soc. 2016, 93, 1615-1624. [CrossRef]

25. Plötz, T.; von Hanstein, A.S.; Krümmel, B.; Laporte, A.; Mehmeti, I.; Lenzen, S. Structure-toxicity relationships of saturated and unsaturated free fatty acids for elucidating the lipotoxic effects in human EndoC- $\beta \mathrm{H} 1$ beta-cells. Biochim. Biophys. Acta. Mol. Basis. Dis. 2019, 1865, 165525. [CrossRef] [PubMed]

26. Lin, C.-Y.; Lu, C. Development perspectives of promising lignocellulose feedstocks for production of advanced generation biofuels: A review. Renew. Sustain. Energy Rev. 2021, 136, 110445. [CrossRef]

27. Lepri, F.G.; Chaves, E.S.; Vieira, M.A.; Ribeiro, A.S.; Curtius, A.J.; DeOliveira, L.C.C.; Decampos, R.C. Determination of Trace Elements in Vegetable Oils and Biodiesel by Atomic Spectrometric Techniques-A Review. Appl. Spectrosc. Rev. 2011, 46, 175-206. [CrossRef]

28. Nezihe, A.; Elif, D.; Özlem, Y.; Tunçer, E.A. Microwave Heating Application to Produce Dehydrated Castor Oil. Ind. Eng. Chem. Res. 2011, 50, 398-403. [CrossRef]

29. Giakoumis, E.G. Analysis of 22 vegetable oils' physico-chemical properties and fatty acid composition on a statistical basis, and correlation with the degree of unsaturation. Renew. Energy 2018, 126, 403-419. [CrossRef]

30. Giakoumis, E.G.; Sarakatsanis, C.K. Estimation of biodiesel cetane number, density, kinematic viscosity and heating values from its fatty acid weight composition. Fuel 2018, 222, 574-585. [CrossRef]

31. Radhakrishnan, S.; Devarajan, Y.; Mahalingam, A.; Nagappan, B. Emissions analysis on diesel engine fueled with palm oil biodiesel and pentanol blends. J. Oil Palm Res. 2017, 29, 380-386. [CrossRef]

32. Sørensen, G.; Sørensen, K.B.; Hansen, H.O.; Nygaard, S.D. Fuel for the Future: Development of New Fuels, e.g., Biofuels. Appl. Microbiol. Mol. Biol. Oilfield Syst. 2010, 5, 219-228. [CrossRef] 
33. Li, B.; Liu, G.; Ren, S.; Chen, L.; Teng, H.; Lu, X.; Gao, J. Non-isothermal crystallization kinetics of waxy crude oil. Pet. Sci. Technol. 2018, 37, 282-289. [CrossRef]

34. Yuan, M.-H.; Chen, Y.-H.; Chen, J.-H.; Luo, Y.-M. Dependence of cold filter plugging point on saturated fatty acid profile of biodiesel blends derived from different feedstocks. Fuel 2017, 195, 59-68. [CrossRef]

35. Lv, P.; Cheng, Y.; Yang, L.; Yuan, Z.; Li, H.; Luo, W. Improving the low temperature flow properties of palm oil biodiesel: Addition of cold flow improver. Fuel Process. Technol. 2013, 110, 61-64. [CrossRef]

36. Wahyudi; Wardana, I.N.G.; Widodo, A.; Wijayanti, W. Improving Vegetable Oil Properties by Transforming Fatty Acid Chain Length in Jatropha Oil and Coconut Oil Blends. Energies 2018, 11, 394. [CrossRef]

37. Wu, L.; Wei, T.-Y.; Tong, Z.-F.; Zou, Y.; Lin, Z.-J.; Sun, J.-H. Bentonite-enhanced biodiesel production by NaOH-catalyzed transesterification of soybean oil with methanol. Fuel Proc. Technol. 2016, 144, 334-340. [CrossRef]

38. Idowu, I.; Pedrola, M.O.; Wylie, S.; Teng, K.; Kot, P.; Phipps, D.; Shaw, A. Improving biodiesel yield of animal waste fats by combination of a pre-treatment technique and microwave technology. Renew. Energy 2019, 142, 535-542. [CrossRef] 